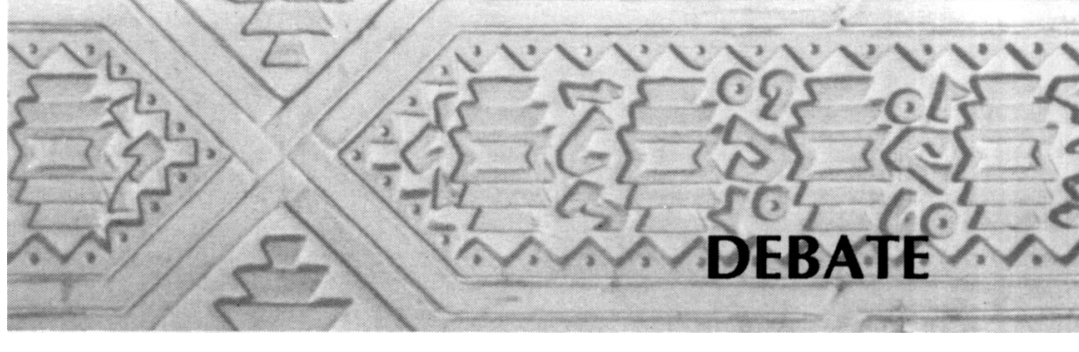

\title{
VENENO E ANTÍDOTO: CIÊNCIA, TECNOLOGIA E OS RISCOS PARA O HOMEM
}

\author{
POISON AND ANTIDOTE: SCIENCE, \\ TECHNOLOGY, AND HUMAN RISKS
}

Nas sociedades contemporâneas, a ciência e a tecnologia converteram-se em poderosas forças estratégicas, e tornaram-se eixos de grandes transformações na saúde, no meio ambiente e em qualquer outra esfera da vida social. A magnitude dessas transformações faz com que não sejam mais responsabilidade apenas dos pesquisadores em seus laboratórios. Passam a envolver inúmeros atores e interesses: a grande indústria, os sindicatos, os militares, os governos, os grupos de cidadãos, enfim, todos os componentes da sociedade. Tais características da ciência e tecnologia fazem com que os laboratórios, espaços por excelência para a geração de fatos científicos e inovações tecnológicas, sejam também o locus estratégico da ação política moderna, de forma direta e indireta, de modo visível ou não para os atores envolvidos.

A utilização em larga escala de substâncias químicas em processos de produção e em produtos é exemplo disso. O desenvolvimento da indústria química e da pesquisa visando a produção sintética de novas substâncias, que já vinham se acentuando desde fins do século XIX, intensificaram-se a partir da Segunda Guerra Mundial. Nos lares, no trabalho industrial e agrícola, nos rios e mares, no chão e na atmosfera, em todo o planeta encontramos substâncias químicas de origem antropogênica, criando muitas vezes riscos à saúde, ao meio ambiente e ao próprio futuro das sociedades humanas. Se por um lado entram na composição dos medicamentos usados para tratar de doenças, por outro são responsáveis por milhares de casos de intoxicação a cada ano, contribuindo para causar lesões, mortes ou efeitos teratogênicos, como na tragédia da talidomida. O mesmo agrotóxico que elimina pragas de plantações, viabilizando latifúndios monocultores elimina a saúde ou a vida dos trabalhadores e famílias expostas à sua ação. O clorofluorcarbono utilizado em aparelhos de refrigeração - geladeiras e condicionadores de ar - alarga dia a dia o buraco na camada de ozônio, contribuindo para o aumento na incidência de casos de câncer de pele. A mesma situação se verifica em cenários diferentes, como na biotecnologia e na engenharia nuclear.

Paradoxalmente, é na própria ciência e tecnologia que se buscam as soluções para os inumeráveis riscos que ameaçam as sociedades contemporâneas e seu futuro. Tecnologias limpas, novas formas de tratar doenças, novos métodos de identificação, análise e monitoramento de riscos são freqüentemente anunciados como soluções na grande imprensa e em periódicos científicos. Alguns céticos consideram que a ciência e a tecnologia serão incapazes de resolver os problemas que engendram, sem trazer novos problemas. Argumentam outros que não se pode abandoná-las, que não há 
regresso possível a um passado idílico. Defendem, alguns destes, a transformação do atual paradigma, a busca de uma nova ciência e de novas tecnologias. As posições variam bastante, indo do mais extremado otimismo ao mais negro pessimismo. $O$ debate prossegue sem perspectivas de solução, mas com uma característica importante: não é mais um debate apenas acadêmico, entre pares dos mesmos campos. Envolve inúmeros atores implicados na preservação da saúde, do meio ambiente e da sociedade como um todo.

Essas e outras questões são discutidas neste debate, de que participam profissionais de destaque em nosso país e no exterior. Arsênio Oswaldo Sevá Filho é professor do Departamento de Energia da Faculdade de Engenharia Mecânica da Universidade Estadual de Campinas (Unicamp). Ele aborda as questões do poder político e econômico que permeiam a ciência, a tecnologia e os riscos. José Manoel Carvalho de Mello é professor na área de inovação tecnológica e organização industrial na Coordenação de Programas de Pós-Graduação em Engenharia da Universidade Federal do Rio de Janeiro (Coppe-UFRJ). Sua contribuição maior vem da sociologia da ciência e da tecnologia, demonstrando o caráter contingente dos feitos científicos e dos artefatos tecnológicos. Luis David Castiel acrescenta a visão sobre os aspectos epidemiológicos que a discussão envolve. Ele é professor e pesquisador da Escola Nacional de Saúde Pública (Ensp). Marcelo Firpo de Souza Porto, professor e pesquisador, meu colega no Centro de Estudos da Saúde do Trabalhador e Ecologia Humana, da Ensp, ressalta que a amplitude do problema exige rever os fundamentos científicos, sociais e éticos de nossa sociedade. A visão de Silvio Funtowicz, pesquisador do Institute for Systems, Informatics and Safety, da European Commission-Jointe Research Centre, nos remete às origens da ciência moderna para apontar o caráter reducionista diante da complexidade dos problemas que enfrenta, principalmente os atuais, para os quais se coloca a necessidade de uma ciência pós-normal.

Carlos Machado de Freitas Pesquisador do Centro de Estudos em Saúde do Trabalhador e Ecologia Humana (Cesteh/ENSP/Fiocruz)

Av. Leopoldo Bulhões, 1480 21041-210 Rio de Janeiro - RJ E-mail: carlosmf@manguinhos.ensp.fiocruz.br 
Seriam as ciências e tecnologias disponiveis na atualidade efetivamente capazes de contribuir para resolver os problemas que provocam?

\section{Arsênio Oswaldo Sevá Filbo}

Não há sinais claros de que sejam capazes de contribuir decisivamente para resolver os problemas atuais.

Comecemos pelo condicional: se tais problemas fossem reconhecidos e destacados como campo relevante de trabalho por parte significativa dos atuais pesquisadores e engenheiros, e se esta coleção de desafios fosse encarada sem omissões nem falseamentos, na formação dos futuros pesquisadores e, em especial, dos futuros engenheiros, aí teríamos os primeiros sinais claros de que, pelo menos, estaríamos lutando para resolver tais problemas.

$\mathrm{Na}$ maneira de formular a questão, senti, e aponto, dois incômodos para quem deve respondê-la. Primeiro, ciências e técnicas estariam realmente disponíveis? Para quem? Com quais finalidades? Segundo, os tais problemas são de fato provocados pela ciência e tecnologia? Será que, ao formularmos desta maneira a questão, não estaríamos de cara eximindo de responsabilidade o poderoso capital financeiro e industrial - aqueles grupos políticos e aquelas organizações econômicas que há dois séculos comandam as aplicações produtiva, militar, repressiva e cultural do conhecimento técnico?

Convém, então, trilhar o caminho de volta, recolocando a constituição dos problemas de risco associados com a ciência e as técnicas. $O$ primeiro ponto a destacar é que muitos dos problemas são socialmente construídos a partir de eventos de risco que têm origem na dinâmica do planeta, ou origem telúrica. Basta registrar que a potência e o momento preciso de ação das forças naturais das tempestades, trombas d'água, erupções vulcânicas, terremotos e tufões são totalmente independentes da vontade humana e, muitas vezes, por nós desconhecidos.

Outro ponto a ressaltar é a origem humana e técnica de muitos dos problemas. Refiro-me aos que são claramente desencadeados por alguma intervenção humana, seja remota ou recente, manifestando-se por meio de seus efeitos cumulativos ou agudos.

Cada vez mais, as situações de risco com maior repercussão social e ambiental resultam de uma sinergia entre os mecanismos do risco telúrico e do risco técnico. Como exemplo, cito os casos cada vez mais comprovados de sismicidade induzida por reservatórios (SIR), com tremores e terremotos em áreas ribeirinhas e próximas do 'lago' artificial, construído para ser 'jazida' de eletricidade. Casos brasileiros são conhecidos nas áreas dos reservatórios de Paraibuna (SP), de Carmo do Cajuru (MG) e na região de Sacramento, no Triângulo Mineiro. Há também muitos registros de epidemias e pragas de mosquitos em lagos de hidrelétricas, como em Tucuruí (PA) e Itaparica (BA/PE).

Ora, numa sociedade como a brasileira, com tanto analfabetismo e escolaridade abortada, com as heranças recentes da censura e centralização, da manipulação de fatos e versões, o obstáculo maior, a prioridade número um consiste na superação da ignorância, da desinformação e no combate à crescente deformação das informações impostas aos cidadãos.

Trabalhadores lidam com produtos cuja fórmula química e efeitos tóxicos desconhecem. Consumidores ingerem produtos que não têm sequer a composição 
detalhada na embalagem. Transeuntes circulam dentro ou perto de instalações de alto risco e em meio ao tráfego de cargas explosivas ou letais. Este é o panorama, sem retoques.

Se isto fosse combatido positivamente, de forma sustentada e entusiástica, num movimento geral de democratização da informação e de prioridade para a educação em todos os níveis, aí sim teríamos outro sinal inequívoco de que as ciências e as técnicas, em algum tempo próximo, poderiam estar disponíveis para quem precisa delas.

\section{José Manoel Carvalho de Mello}

Contribuições recentes no campo dos estudos em ciência e tecnologia têm destacado o fato de que tecnologias não são puramente tecnológicas, mas sim artefatos heterogêneos que incorporam acordos e compromissos.

Tecnologias sempre incorporam compromissos. Política, economia, conceitos científicos, noções de estética e de valor, preferências profissionais, predisposições e habilidades, ferramentas de design compõem, junto com as matérias-primas disponíveis, os ingredientes utilizados na concepção e construção de artefatos.

Algumas vezes falham, mas freqüentemente funcionam. O seu funcionar ou falhar é sempre moldado por uma gama de fatores díspares. Assim sendo, as tecnologias poderiam ter sido moldadas de outro modo.

A meu ver, essa é a contribuição-chave para a compreensão delas. Implica dizer que não evoluem sob o ímpeto, apenas, de uma lógica científica interna, não possuem um momentum próprio. Em outras palavras, não há determinismo tecnológico.

O caráter contingente da tecnologia implica o abandono de quaisquer explicações reducionistas, sejam elas calcadas no determinismo tecnológico ou social. Não se assume mais que o técnico ou o social ou o econômico ou, ainda, o político estejam na raiz das mudanças tecnológicas, dirigindo-as.

O desenvolvimento tecnológico é um processo social. Não há, de um lado, a tecnologia e, do outro, o social, como dois mundos ou processos separados. Certamente, a sociedade é modelada pela tecnologia, mas a tecnologia é também modelada pela sociedade. Estamos diante de um tecido sem costura.

Tecnologias são frutos de relações sociais, econômicas e técnicas já existentes. Ao mesmo tempo que nascem da estrutura de oportunidades e restrições existentes, estendem, moldam, retrabalham ou reproduzem tal estrutura por caminhos não previsiveis. Tecnologias estabilizam-se quando - e somente quando - se estabilizam as relações heterogêneas nas quais estão implicadas e de que formam uma parte.

A evolução delas depende, em última instância, de escolhas da sociedade. Considerado em escala micro, o processo pode parecer autônomo. Considerado em contexto mais amplo e em escala de tempo maior, a evolução das tecnologias não aparece menos adaptada a seu ambiente social do que a evolução das espécies a seu ambiente natural. Se o dinamismo do capitalismo moderno institucionalizou-se nas estruturas de pesquisa e inovação das grandes empresas, nos laboratórios públicos, nas universidades, o produto deste dinamismo não se impõe de fora, como um destino.

Em resumo, não nos parece correto imputar às ciências e às tecnologias per se as causas das mazelas do progresso tecnológico. 


\section{Marcelo Firpo de Souza Porto}

A resposta genérica para esta pergunta também genérica, e complexa, é não. A velocidade da criação e difusão de novas tecnologias nos últimos 150 anos vem sendo bem maior do que a capacidade da própria ciência e dos aparatos institucionais existentes na sociedade de reconhecerem seus impactos sobre a saúde e o meio ambiente, e de criarem mecanismos efetivos de controle. Vários ditos populares condenam as conseqüências da pressa, e os resultados desta era do capitalismo industrial marcada pela velocidade trazem à tona o poder destrutivo da criação moderna.

A história dos acidentes industriais e das doenças do trabalho permitem visualizar este movimento com especial clareza. As invenções - como tecnologias de fabricação, máquinas ou novas substâncias químicas - surgem pela evolução científica de certas disciplinas e do trabalho de laboratórios de pesquisa e desenvolvimento (P\&D) em articulação com interesses econômicos e de mercado. Num segundo momento, difundem-se enquanto processos ou produtos. Num terceiro momento, começam a ser discutidos os efeitos sobre o meio ambiente e sobre a saúde de trabalhadores, consumidores e outros grupos populacionais, e com freqüência a partir da constatação de conseqüências como acidentes com mortes ou casos de doenças graves. Num quarto momento, trava-se uma batalha política, técnica e jurídica na qual diversos atores e interesses se articulam em redes que condicionam o teor das respostas institucionais e legais para o controle dos riscos gerados pelos processos e produtos em circulação já há décadas. Sejam ou não eficientes, as políticas e açôes desenvolvidas para controlar o problema surgem normalmente, depois de já terem ocorrido diversos efeitos para a saúde e o meio ambiente, restando, quando muito, a possibilidade de um conjunto reduzido de medidas mitigadoras.

Outra questão atual, que revela a dimensão dos riscos tecnológicos contemporâneos, é a amplitude e complexidade adquiridas por diversos problemas ambientais modernos, que passam a ser cada vez mais transnacionais e globais. É o caso das mudanças climáticas decorrentes da concentração de dióxido de carbono e outros gases na atmosfera; diminuição da camada de ozônio pela emissão de clorofluorcarbonos (CFCs); contaminação de oceanos; contínua destruição de ecossistemas com a decorrente extinção de espécies vegetais e animais, reduzindo a biodiversidade do planeta; circulação de substâncias e resíduos perigosos, incluindo a exportação de lixo industrial para países pobres. Todos estes exemplos mostram a crescente gravidade e complexidade dos riscos tecnológicos contemporâneos, em situações onde a incerteza e a ignorância somam-se aos problemas políticos e éticos decorrentes dos processos decisórios que definem os limites do permitido e as políticas de controle dos riscos.

Poder-se-ia argumentar que tais problemas não decorrem de uma limitação da ciência e tecnologia per se, mas sim dos processos políticos e, em última instância, das atuais estruturas sociais. Por outro lado, reina ainda forte crença - sobretudo no meio científico e entre os profissionais que atuam em P\&D - de que o desenvolvimento tecnológico é interativo e ilimitado em sua capacidade inovadora, recriando sucessivamente novas capacidades de superação de problemas gerados em fases anteriores. Nesse tipo de discussão, corre-se o risco de se cair em disputas circulares de crenças, ou no dilema do ovo ou da galinha. Ainda assim, como ponto de partida, sugiro o reconhecimento de três questões básicas: a gravidade dos riscos tecnológicos que exigem esforço concentrado para serem reconhecidos como problemas prioritários; 
a natureza complexa e multidimensional dos riscos, requerendo-se integração e novas sínteses de campos de conhecimento e práticas institucionais para se obter diagnósticos e processos decisórios de melhor qualidade; e, por último, a mudança compartilhada de paradigmas no conjunto das disciplinas científicas e tecnológicas, superando-se a visão hegemônica do homem na sua relação com a natureza, em seu papel de dominador e instrumentalizador. Os desafios exigem uma nova ciência. Autores como Silvio Funtowicz e Jerolme Ravetz denominam como pós-normal a nova epistemologia necessária para a resolução desses problemas ambientais tão complexos.

Muito se fala atualmente na necessidade de uma 'nova' ciência e uma 'nova' tecnologia. Quais seriam seus componentes e o que as diferenciaria das ciências e tecnologias 'tradicionais'?

\section{José Manoel Carvalbo de Mello}

Se compartilhamos a idéia de que artefatos tecnológicos também são construções políticas e sociais, no centro de qualquer tentativa de controlar seus perigos, seus malefícios, tem de estar o entendimento de que a tecnologia condiciona o contexto social na mesma medida em que é por ele condicionada.

As tecnologias contemporâneas são extremamente complexas, tanto por dependerem, para sua produção, de conhecimentos e instrumentos científicos cada vez mais sofisticados, como por dependerem, em seu funcionamento, de organização cada vez mais complexa.

$\mathrm{Na}$ verdade, estamos diante não de tecnologias, e sim de sistemas tecnológicos: utilizar um computador, ligar uma tomada de luz, passar um fax são atos que implicam o ingresso numa rede de relações sócio-técnicas em que intervém uma gama enorme de fatores, sem os quais a própria utilização do produto técnico seria impossível.

Acidentes tecnológicos podem ser vistos de maneira provocativa, mas profunda, não como eventos anômalos, inesperados, súbitos, mas sim como eventos normais. Se acontecem sem notícia prévia é porque criamos uma barreira artificial entre o tecnológico e o social, imputando ao primeiro uma falsa imperfeição. E porque aceitamos uma relação estável entre máquinas, pessoas e ambiente como o único estado de coisas possivel.

Se passarmos a olhar a tecnologia como parte de sistemas heterogêneos, que combinam elementos sociais e técnicos num equilíbrio frágil, teremos um antídoto a estas confortáveis assunções. Só assim será possível providenciar artefatos tecnológicos que detenham as chaves dos acidentes ocorridos e dos que irão ocorrer.

Estudos recentes sobre desastres tecnológicos têm salientado as dimensões sociais, políticas e até morais de tais eventos. Nova ênfase tem sido dada ao contexto organizacional em que se situa a tecnologia. Com isso, há o reconhecimento de que políticas corretivas devem visar não só o design de artefatos, como também as práticas humanas e pressuposições que determinam seu gerenciamento e uso.

Esforços para encontrar medidas para a futura prevenção passam por ampla crítica social, contemplando, por exemplo, a tentativa de entender os defeitos de nossas criações tecnológicas. Com essa postura, aprofundamos nossa compreensão sobre a sociedade que habitamos.

Meros ajustes nas tecnologias e pequenas melhorias organizacionais, por si só, não são suficientes para enfrentar a situação de 'normalidade' dos desastres tecnológicos. 
É preciso suplementá-las com mudanças estruturais concernentes a aspectos macroscópicos de política, economia e cultura.

Em primeiro lugar, é necessário reexaminar os meios de controlar a proliferação de tecnologias e riscos tecnológicos. É preciso viabilizar uma escolha social mais democrática da tecnologia, garantir ao público o fornecimento de informações relevantes sobre riscos e, também, sua participação no processo de tomada de decisões.

É importante enfatizar a impossibilidade de separar ciência e política nos processos de regulamentação e controle. Nessa perspectiva, cientistas e, naturalmente, especialistas em riscos têm um papel modesto porém importante a desempenhar, informando sobre as decisões tomadas para regulamentar e controlar. Conhecimento científico e julgamento podem orientar escolhas regulamentadoras, mas não devem nem podem responder às questões últimas que se busca regulamentar, já que ocorrem, fundamentalmente, em esferas de negociação política.

Nesse contexto, é fundamental que cientistas e especialistas em riscos compreendam melhor o processo de construção do conhecimento científico, sua dimensão social, as incertezas e indeterminações que lhes são inerentes.

Em segundo lugar, torna-se necessário repensar o próprio modelo econômico, para que se obtenha o desenvolvimento sustentável, isto é, uma relação estreita entre crescimento econômico, preservação ambiental e qualidade de vida.

Mudanças culturais são, também, indispensáveis. Precisamos rever completamente nossas cosmologias, visões de mundo, que valorizam o individualismo e o consumismo e nutrem pouco respeito pela natureza e pelo comunitário.

Concluindo, mais do que uma 'nova' ciência e tecnologia, o que se necessita é de uma 'nova' sociedade.

\section{Silvio Funtowicz}

In order to answer the questions framing the issues for debate, we have to look closely at the origins of the contemporary scientific system, which includes science and science-based technology.

The great achievement of modern European science was the successful simplification of complexity. But, at what price success?

The underlying belief of the founders of modern science was that uncertainty could be eliminated, and that the power of reason would conquer ignorance. It was also assumed that uncertainty was the result of human passions. In these terms, the task was the creation of a method that would ensure the separation of reason and passion, and the goal was the discovery of the pure hard facts, uncontaminated by soft values.

The emerging scientific method included the assumptions that the natural system could be divided into isolated quasi stable components, and that the objects of study could be separated from the subject studying them. Disciplinary science (which is the basis of the University system) and the myth of value-free, neutral science (which legitimises expertise), are the direct consequences of these endeavours. At the same time as Europe was conquering the new worlds, modern science was conquering Nature, and the two conquests were closely related.

The success of science also had other consequences in relation to the issues being debated. It provided the modern states with a legitimating model of 'rational' decision- 
making, in which correct actions followed the discovery of true facts. In other words, the Good was implied by the True. Rationality became synonymous with "scientific rationality" and knowledge with "scientific knowledge". Other claims to rationality or forms of knowledge were dismissed as illegitimate, and even practical knowledge based on craft skills was considered a lower class of knowledge.

The scientific system has also provided modern societies with a novel understanding of danger. Dangerous situations are labelled 'risks', and their management is mediated by "experts systems" (science, science-based technology and scientific experts). The model is designed to appear purely rational, but passion is implicitly present, in the trust that is required for risk management to operate successfully. Recent episodes, such as "mad cow disease" (BSE), show that the "mediation mechanism" has become brittle. There is now a widespread feeling that the scientific system (including sciencebased technology) is responsible for many of our perceived environmental and health problems.

The Good has also been compromised by a scientific system closely associated with an economic theory which privileges economic growth as the only form of development, has a total disregard for questions of fairness and equity, and professes a reckless "technological optimism".

If this is the state of affairs nowadays, then the issues for debate could be formulated in the following way: Is the science and technology that created the pathologies of our industrial system, the same science and technology that will contribute to resolve them? And, if the answer is no, what would be the task of a "new science"?

Clearly, the task can no longer be solely the advancement of knowledge, motivated by a mixture of scientists' curiosity and sponsors' profit. Rather, it will be devoted to the resolution of issues in health, at the human, community and environmental scales. In this, its method will necessarily be some sort of simplification of complexity. This time, however, it will have to be done in the context of irreducible uncertainty and even ignorance. The basic assumptions of modern science will have to be modified for the development of a new, issue-oriented science. Disciplinary science will have to give way to trans-disciplinary science, and reason will have to be reconciled with passion. This new practice of science we call Post-Normal; and it is relevant and effective when facts are uncertain, values are in dispute, stakes are high and decisions urgent.

In Post-Normal Science, Quality replaces Truth as its organising principle. The task is no longer of individual experts discovering "true facts" for the determination of "good policies". Rather it involves an extended community, which evaluates and manages the quality of scientific inputs, for complex decision-making processes whose goals are negotiated from conflicting perspectives and values.

We will still need good quality traditional science and technology. Their products, however, will have to be embedded in an integrating social process. In this way, the scientific system will become a useful input to novel forms of policy making and governance.

The modern scientific system and its model of decision-making could not by itself provide the whole answer to issues of health at the individual, community or environmental scales. Health can only be comprehended as a systemic concept, which is also complex because it includes a plurality of legitimate perspectives. Post- 
Normal science provides a context, practice and commitment in which these real issues of health have a chance of genuine resolution.

\section{Marcelo Firpo de Souza Porto}

Considero alguns elementos centrais para se pensar a estrutura e a prática de uma nova ciência reconstruída pelo paradigma ecológico.

Primeiro, incerteza e complexidade estão intrinsecamente relacionadas ao conceito de risco. Colocar a incerteza como questão relevante para a avaliação de riscos tecnológicos possui implicações tanto teórico-metodológicas quanto éticas e políticas. Tal noção também se baseia no reconhecimento, propiciado pela ecologia, de que a natureza é composta por sistemas complexos inter-relacionados bióticos e abióticos. $O$ aumento da intervenção humana sobre a natureza, concomitante à expansão industrial e tecnológica, produz, além de desastres mais imediatos, como acidentes localizados, catástrofes de médio e longo prazos em decorrência da desestabilização de equilíbrios homeostáticos que permitem às espécies, inclusive a humana, se manterem vivas. No âmago da nova prática científica, encontra-se o reconhecimento do limite dos modelos científicos usados para interpretar a natureza e avaliar o impacto das intervenções humanas sobre o ambiente. Os interesses econômicos em jogo, a soberba e o corporativismo existentes em grupos de cientistas e em instituições dificultam o reconhecimento das incertezas e ajudam a mantê-las encobertas, perpetuando estados de ignorância, já que não se sabe o que não se sabe.

A noção de complexidade, por sua vez, não envolve apenas aspectos técnicos: compreende a interação destes com a própria estrutura das sociedades. Os modelos de ciência e tecnologia, e os processos decisórios que definem políticas públicas e regulamentações integram o conjunto de culturas, interesses e forças em ação. Portanto, outra marca distinta da nova prática científica e institucional consiste em integrar aspectos técnicos e sociais - ou os campos hard e soft do conhecimento - sem deixar de incorporar as incertezas decorrentes da própria organização social. Tais diretrizes não são novas, mas as práticas atuais, em particular as de formação de cientistas e tecnólogos, ainda se encontram muito aquém delas.

O segundo elemento central para a estruturação da nova ciência é a capacidade de diálogo, quer entre os especialistas, articulados por marcos referenciais comuns, equipes multiprofissionais e abordagens interdisciplinares, quer dos especialistas com os diferentes atores sociais envolvidos nos problemas em discussão, pautando-se esta relação em princípios éticos básicos, como o reconhecimento dos limites do conhecimento dos primeiros e a aceitação do conhecimento e participação dos outros interlocutores. Tal aceitação é ainda mais importante quando os atores estão envolvidos diretamente nas situações de risco e em seus efeitos, como os trabalhadores e as populações que labutam e residem em áreas críticas. Por fim, ao mito dos laboratórios e especialistas fechados em si mesmos, aproximar os setores de planejamento e decisão das questões de saúde e ambiente e da participação social abrangente constituem os desafios centrais da nova prática científica e institucional. O especialista dos novos tempos é aquele que sabe construir pontes entre seu campo específico e outros campos do conhecimento, e laços de solidariedade articulando redes sociais de defesa da vida e do ambiente. 


\section{Arsênio Oswaldo Sevä Filho}

Comecemos pela qualificação de como funcionam a ciência e a tecnologia na sociedade de hoje. A produção e utilização dos resultados da ciência e das técnicas são socialmente determinadas e historicamente datadas. Sua publicização - há muito tempo controlada pelo Estado e pelas Forças Armadas, e até poucos séculos atrás também pelas igrejas - é hoje domínio da cultura, da mídia e da formação de elites tecnocráticas e gerenciais. O controle da informação, da repercussão e dos desdobramentos da ciência e técnica na vida social é campo de ação prioritário das atuais corporações financeiras e industriais.

Em seguida, prefiro não alimentar a dicotomia entre o 'novo' e o 'tradicional', pois a utilização dela assim, genericamente, no amplo e heterogêneo campo da ciência e tecnologia, tende à rotulação e ao estigma, que são incompatíveis com a atitude fundamental do pesquisador. A abertura mental, a pluralidade, o espírito de dúvida e a liberdade de crítica são fatores sem os quais não se pode investigar a realidade nem as relações humanas. Além disso, é recomendável que nós, cientistas e pesquisadores, cultivemos o respeito pelo patrimônio coletivo, cultural e artístico de tantas civilizações e povos. Que possamos compreender e valorizar os fracassos e sucessos dos que vieram antes, e fazer nossas correções de rumo.

Muitos de nossos predecessores foram geniais. Seus métodos são, simplesmente, insubstituíveis. Por exemplo, há cento e tantos anos, antes de a fotografia ser inventada e tornada acessivel, os viajantes, os cronistas faziam manualmente seus desenhos e croquis, seus cálculos e agendamentos. Os empreendimentos da conquista colonial arregimentavam cientistas naturais, cartógrafos, agrimensores, tradutores, mais tarde antropólogos, geógrafos... Enfim, tomavam-se as providências possíveis, na época, para obter a apreensão da realidade e da totalidade de uma cena, de um trajeto, de uma situação social e econômica. Muitas vezes, a 'descoberta' revelava um grupo humano vivendo melhor que os brancos conquistadores, uma civilização com avanços técnicos maiores em alguns setores do que a européia.

A julgar pelos meios que podiam empregar, os agentes técnicos da colonização pesquisavam mais e melhor do que nós, aprendiam de forma muito eficaz. Nada assegura que possamos promover o mesmo tipo de aprendizado com os recursos fantásticos dos computadores e da Internet.

Digo mais: nossos predecessores constataram e reconheceram que os conhecimentos práticos sobre a natureza, as águas, os solos e subsolos, os materiais e as energias, o mundo das ferramentas e das máquinas sempre se desenvolviam em paralelo à ciência institucional. Exatamente por isso pilharam, barganharam ou, de alguma outra forma, se apropriaram das fontes dos chamados conhecimentos tradicionais, originários da prática de quem trabalhava, da memória coletiva dos povos indígenas, o saber do morador antigo, do operário... Aprendemos com nossos predecessores que esta sabedoria popular é tão importante quanto as fontes oficiais do conhecimento acadêmico, jurídico ou administrativo - às vezes mais importante até.

Retornando, então, ao foco da questão formulada: há necessidade crucial de mudanças, mais do que isso, há necessidade de rupturas com o que viemos fazendo e de abandono de uma parte do legado que as atuais gerações receberam - armas de guerra, radiativas, químicas e bacteriológicas; energia nuclear e suas sucatas quase eternas; muitos dos combustiveis e dos produtos químicos que são usados hoje, enfim, os sistemas complexos e perigosos já conhecidos dos leitores de Charles Perrow, Alain Wisner, Patrick Lagadec, entre outros. 
E, mesmo nos setores onde o risco é menor, menos evidente ou menos grave, há muito o que fazer. Temos que chegar a uma atividade econômica mais digna, que remunere melhor, que mate e adoeça menos quem trabalha. Se a meta incluir, sem mentiras e maquiagens, uma produção mais segura, mais limpa, menos destruidora de recursos, que provoque menos alterações no ambiente, teríamos aí uma pauta mínima para uma ciência mais atuante, numa sociedade mais democrática e menos corrompida.

Porém, isto exigiria romper também com a conivência e até mesmo a subordinação dos pesquisadores e engenheiros em relação ao grande capital e suas estratégias fundamentais. O restante — uma 'nova' prática científica e tecnológica — viria em decorrência.

Qual sua avaliação sobre a participação da sociedade no controle das ciências $e$ tecnologias, desde os processos de inovação até os decisórios? Julga bem-sucedidas as tentativas de estabelecer politicas de gerenciamento dos riscos à saúde e ao meio ambiente?

\section{Arsênio Oswaldo Sevá Filho}

Esta participação da sociedade, no Brasil, é inexistente. Só ocasionalmente associações ou grupos de pesquisadores intervêm em casos importantes. Por exemplo, no repúdio à ditadura e ao acordo nuclear com a Alemanha por parte da Sociedade Brasileira de Física (SBF) — os físicos da Sociedade Brasileira para o Progresso da Ciência (SBPC) - há vinte anos.

Tivemos por aqui algumas situações comparáveis às européias, norte-americanas, chinesas, japonesas ou russas, no mesmo período histórico, isto é, nas últimas duas a três décadas: a divulgação da situação crítica de Cubatão (SP) e dos casos de impacto ambiental e social de barragens, como de Balbina (AM) ou Tucuruí (PA). Podemos citar a anulação de projetos de investimento que despertaram reações da sociedade local, como foi o caso da hidrelétrica de Capanema (PR), das centrais termoelétricas movidas a resíduo de petróleo em Paulínia e em São José dos Campos (SP), da fábrica de celulose Norcel, na Bahia. E, ainda, as recentes reações contrárias ao poderoso lobby que articulava a instalação de incineradores de lixo doméstico nas cidades de médio e grande porte.

Mas nesses momentos o que se buscou foi a participação da sociedade em decisões envolvendo investimentos de grande porte, e não na escolha desta ou daquela tecnologia industrial ou energética. Enquanto isso, moradores de muitas regiões no país sofreram inúmeras derrotas e enfrentaram fatos consumados.

Assim, devolvo a pergunta: com nossa bagagem escravista e coronelística, depois de três décadas devotadas à repressão e à centralização - inclusive nos meios científicos e acadêmicos - , como poderíamos saber o que se passa no mundo da produção e do comando político da sociedade? Como poderíamos participar do controle das atividades, sem legitimar meramente o que já foi decidido pelos que sempre decidem?

Quanto à segunda parte da questão, costumo repetir que risco não se gerencia, risco se combate! Suponho que sejam bastante úteis algumas iniciativas políticas e legislativas tomadas em outros países, por exemplo, os registros de acidentes graves do tipo MHIDAS (Major Hazard Incidentes Data Systems) da Inglaterra, ou MARS, o similar da União Européia, ou, ainda, os procedimentos tipo APELL (Awareness and 
Prepareness for Emergencies at Local Level), adotado nos Estados Unidos e em algumas regiões industriais européias. Considero igualmente louvável o relicenciamento e a publicização de informações técnicas e econômicas de centenas de instalações perigosas na Europa após a diretriz CEE/502/81, conhecida como Diretriz Seveso. Foi também marcante o ato da Environmental Protection Agency, nos Estados Unidos, sobre o direito da comunidade de conhecer (Community Right-to-Know). Tais iniciativas indicam caminho promissor, embora árduo, pois o trunfo político existe e é valioso, e, por essa razão, pode ser capturado e metabolizado pelo meio empresarial e financeiro, que impõe e imporá sempre limites duros à abertura das informações até aqui sonegadas.

Neste aspecto, o que é o Brasil dos últimos anos? O país do incêndio na favela de Vila Socó após mais de doze horas de vazamento de gasolina no manguezal, em 1984. O país da tragédia do trem de passageiros destruído em outubro de 1996 por um comboio de minérios que descia a serra, sem freios, avisando sobre a colisão iminente...

É o país das setenta vítimas da hemodiálise em Caruaru (PE) contabilizadas até outubro de 1996, das dezenas de manifestantes pobres executados a tiros em Corumbiara (RO) e em Eldorado dos Carajás (PA), o país das dezenas de mortos e centenas de feridos na explosão do shopping de Osasco (SP), das epidemias recorrentes de cólera, dengue, meningite, leptospirose. O campeão de acidentes de trabalho, da omissão generalizada dos dados de doenças ocupacionais e dos muitos nexos causais óbvios, ou facilmente comprováveis, entre estas doenças e o ambiente e as condições de trabalho.

É também o país dos conluios entre empresas e organismos de controle ambiental como a Fundação Estadual de Engenharia do Meio Ambiente (Feema-RJ), a Companhia Estadual de Tecnologia e Saneamento Ambiental (Cetesb-SP), a Fundação Estadual de Proteção Ambiental do Rio Grande do Sul (Fepam-RS) ou a Fundação Estadual do Meio Ambiente de Minas Gerais (Femam-MG). O país dos favelados que roubam um organo-clorado usado como isolante/refrigerante em transformadores elétricos - óleo ascarel - estocado irregularmente por uma empresa pública para fritar peixes e bronzear a pele. É ainda o país dos oito incineradores licenciados para queima de resíduos perigosos e de dezenas de fornos de indústrias cimenteiras utilizados, sem o devido licenciamento, como incineradores dos mesmos resíduos.

Enfim, neste momento e em relação a este assunto, cabe apenas proclamar, em alto e bom som, que no Brasil nada é bem-sucedido, a não ser a contabilidade neoliberal. Graças a ela, nossos recursos e o suor de nossos trabalhadores resultam, dia após dia, nos fluxos de renda expatriada para bancos e investimentos pessoais no exterior, riqueza que alimenta um 'bolo delfiniano' de renda interna cada vez mais concentrada nos bolsos de poucos por cento sempre mais ricos.

\section{Marcelo Firpo de Souza Porto}

A divisão internacional do trabalho, dos riscos e benefícios gera contextos totalmente diferentes tanto para o diagnóstico como para a análise dos problemas de gerenciamento de riscos e encaminhamento de soluções. Em países de economia semiperiférica como o Brasil, mesclam-se riscos tecnológicos de ponta - como nas indústrias nuclear e petroquímica - com riscos industriais e ocupacionais primitivos e já relativamente bem controlados em países de economia central. Isso aumenta eventualmente a 
complexidade da análise e resolução de problemas. Em riscos de menor complexidade técnica - como acidentes nos setores metalúrgico e de construção civil - a recorrência do descontrole está relacionada à exclusão social e à não universalização dos direitos de cidadania modernos. Tais iniqüidades possuem implicações diretas para as políticas de gestão da força de trabalho: relações trabalhistas perversas e práticas institucionais acumpliciadas com a manutenção do status quo, favorecendo o gerenciamento artificial de riscos. Já para os riscos tecnológicos mais complexos, a sua exportação, a existência de duplo padrão em empresas transnacionais que operam em condições mais precárias em países como o Brasil, a degradação de processos de fabricação com a transferência de tecnologias e a falta de recursos e políticas para gerenciar riscos específicos e complexos - como nos casos das tecnologias químicas, nuclear e engenharia genética - podem agravar a vulnerabilidade de determinadas populações. Nesse sentido, a articulação entre risco tecnológico e cidadania e o tratamento privilegiado de trabalhadores e populações socialmente excluídas como objetos da investigação e sujeitos da transformação social constituem estratégias relevantes para este campo na América Latina.

\section{Luis David Castiel}

Minha formação pertence à área biomédico-epidemiológica. Portanto, não enfocarei aspectos de saúde ambiental, biossegurança, toxicologia ou o campo da saúde ocupacional. Independente disto, considero que, sem as reflexões produzidas pelas ciências humanas e sociais, em geral, e pela sociologia da ciência, em particular, a abordagem dos problemas em foco tende a ficar limitada e, certamente, pouco proveitosa, em termos analíticos.

De início, pretendo aproveitar-me do sugestivo título deste debate para situar a perspectiva que proponho desenvolver. Partindo dos possíveis significados do termo "veneno", quero enfatizar uma acepção menos empregada. Veneno costuma ser encarado como substância que altera/destrói as funções vitais. Nesse sentido, temos como palavras correlatas "peçonha" e "tóxico". Mas veneno também pode estar referido a "vírus", enquanto elemento gerador de "doença". Ou, mais especificamente, à característica de contagiosidade dessa entidade etiopatogênica. Nesse caso, os antídotos seriam constituídos, a princípio, pelos recursos tecnológicos biomédicos, tanto diagnósticos como terapêuticos, dirigidos à resolução de tais agravos.

Então, ocorre-nos pensar nas doenças infecciosas ditas emergentes e reemergentes e nos respectivos esforços para enfrentá-las. No caso específico da Aids, tivemos, recentemente, depois de mais de uma década e meia de reveses nas tentativas de controle/tratamento, com correspondente atmosfera de frustração e medo, o surgimento de uma expectativa esperançosa. Mediante técnicas de manipulação molecular, houve o surgimento de novas drogas que enfrentam, com maiores possibilidades de êxito, as 'artimanhas' proliferativas do HIV no sistema imune. Nesse caso, parece, as tecnologias biomédicas conseguiram produzir, apesar dos custos predominantemente elevados, indícios de 'contravenenos' que podem vir a 'neutralizar' a ação virulenta deste agente infeccioso.

No entanto, há um curioso efeito colateral apontado em recentes estudos das práticas sexuais consideradas de risco. Diante dos sinais, ainda incipientes, de eficácia medicamentosa está sucedendo certo afrouxamento das medidas preventivas de 
proteção, chamadas 'sexo seguro'. Ao que parece, não basta que os recursos tecnológicos proporcionem enfrentamento mais eficaz das doenças se estas envolvem, também, comportamentos e práticas arraigadas em dimensões da intimidade e da identidade sexual dos indivíduos, na ambiência de nossas complexas sociedades contemporâneas.

Outro exemplo bastante sugestivo da aliança "desenvolvimento tecnológico novos 'venenos' e 'antídotos', é a proliferação da bactéria Legionella pneumophila, responsável por graves quadros pneumônicos, nos dutos de grandes sistemas de refrigeração de ar, próprios de edificações modernas, como hotéis e shopping centers. Nesta situação, há técnicas moleculares (reação em cadeia da polimerase, por exemplo) que permitem a deteç̧ão das possíveis fontes de infecção do agente microbiano.

Mas diante das alterações das relações eco-sócio-econômicas e culturais geradas na tardo-modernidade permanecem surgindo 'novas' doenças ou outras formas de 'antigas' moléstias para as quais ainda não se descobriram 'antídotos preventivos' eficazes, tampouco formas de controle efetivas de formas microbianas emergentes - bactérias, fungos, riquétsias, vírus e, inclusive, partículas protéicas "degeneradas", os príons.

Por outro lado, diante da ampliação generalizada da sobrevida em vários cantos do mundo, as doenças crônico-degenerativas constituem problemas epidemiológicos cada vez mais sérios, tanto em termos de seus padrões de ocorrência, como em relação às tentativas de discriminar seus respectivos fatores de risco.

Nestas circunstâncias, a perspectiva do risco se alia aos avanços nos procedimentos diagnósticos e testagens preditivas mediante técnicas de manipulação do DNA recombinante, propiciando a ampliação dos conhecimentos acerca das seqüências causais nos processos de carcinogênese. Isto se dá através da verificação das exposições ambientais dos indivíduos sob a forma de doses internas que provocam alterações no DNA em tecidos específicos e as conséqüentes respostas orgânicas (produtos genéticos anormais, mutações).

Ao lado dos indiscutíveis progressos na capacidade de detecção carcinogenética e nas tentativas de regular e evitar exposições nocivas no âmbito da toxicologia, é possivel delinear o aparecimento de uma ideologia de controle de comportamentos sociais e individuais (estilo de vida) e busca da saúde perfeita (seguindo as idéias de Lucien Sfez) no sentido de moderar/evitar exposições danosas. Gera-se assim um novo panorama sócio-cultural e econômico, com a eclosão de novos produtos, serviços e profissionais e a criação de novos mercados.

Importa, ainda, pensar no 'casamento' do conceito de risco com a idéia de virtualidade. Aqui, peço licença para uma breve digressão. Aplicado à idéia de risco, "virtual" opõe-se a "atual": designa algo que não aparece explicitamente mas existe como faculdade, latência, passível de se realizar. Mas há a oposição com "real" que se enraíza na ótica, no estudo dos espelhos, conforme a divergência/convergência dos raios luminosos nos sistemas especulares: "imagem virtual/real". Pode ainda estar referido à produção "artificial" de alguma coisa - "virtual" versus "natural" vinculando-se, nesse caso, à idéia de simulação e modelagem corrente em sistemas computacionais e em outros recursos produtores de representações do real, de simulacros.

A referência a sistemas computacionais veicula usos mais populares do adjetivo "virtual" - sexo virtual, por exemplo, significa o acesso, via Internet, a sites considerados pornográficos. Mas, curiosamente, "virtual" relaciona-se a "virtude", na acepção de 
"força efetiva", "eficácia", "poder". Por exemplo: uma "simpatia com a virtude de curar dor de cotovelo". O conceito de risco também inclui esta característica, pois procura definir exposições com a virtude de gerar determinados agravos...

É inevitável admitir o vigor presente na categoria de risco e em seus variados discursos e propostas de intervenção. Todavia, os efeitos colaterais não são menos evidentes em nosso cotidiano, traduzindo-se na preocupação constante de convívio com exposições e seus possíveis agravos. É importante ter em mente que o afã de controle em nossa civilização cria um efeito colateral: o clima de incerteza e insegurança que paira sobre nós. A tal ponto que não é absurdo cogitar-se nos riscos dos riscos. Ou seja, os riscos de sermos emocionalmente afetados por essa ameaçadora proliferação de riscos (reais ou imaginários) veiculada pelas disciplinas 'riscológicas'.

Em síntese, é preciso ter em mente a dimensão múltipla da 'relatividade' do risco: é um construto produzido em uma época particular, que pode ser caracterizada como tardo-modernidade; está ligado a determinada visão do mundo e do que é a experiência humana; os enfoques teóricos, conceituais e metodológicos adotados na produção dessa noção enfatizam seu caráter probabilístico e as respectivas conseqüências. As pessoas lidam com os seus riscos (e os dos outros) de variados modos, que ultrapassam os saberes científicos e que mesclam dimensões simultaneamente biológicas, psicológicas e sócio-culturais (L. D. Castiel, 'Vivendo entre exposições e agravos: a teoria da relatividade do risco', História, Ciências, Saúde - Manguinhos, vol III (2), pp. 237-64, jul.-out. 1996).

De um modo geral, nessa primeira rodada de perguntas e respostas, as respostas caracterizam a ciência, a tecnologia e os riscos que geram para o bomem, como resultados bistóricos e sociais de nossa civilização, agravados em realidades como as que vivemos no Brasil. As alternativas possiveis passariam, necessariamente, pelo reconbecimento de que ciência, tecnologia e riscos são produtos bistóricos e contingentes; por conseguinte, exigem o reconbecimento das complexas inter-relaçôes que caracterizam sua dinâmica e as incertezas que as acompanbam num mundo permeado por questões culturais e de poder.

No entanto, permanece uma divida. Os aspectos citados em todas as respostas não parecem constituir, necessariamente, um antídoto capaz de eliminar de vez o problema dos riscos - se é que bá antídoto possível. O que parece estar sendo proposto é a construção de uma ciência e uma tecnologia em que os riscos do veneno - ou talvez o veneno dos riscos - e seu antidoto se misturem e se tornem mais transparentes. Obviamente, a solução pressupõe sociedades cada vez mais democráticas.

Feitas estas considerações, gostaria que vocês respondessem a mais uma questão para finalizar o debate: a transparência e a democratização das decisões envolvendo ciência, tecnologia e riscos podem, efetivamente, constituir um antídoto contra os riscos? Ou essa transparência e democratização propiciam apenas mero reconbecimento de nossos limites enquanto "senbores da natureza" $e$, por conseguinte, da complexidade $e$ das incertezas inerentes ao nosso mundo, levando-nos a mudanças sociais e culturais mais do que a qualquer outra coisa?

\section{Silvio Funtowicz}

Democratization is a way of recognizing our limits, the limits of knowledge, like the need to adapt government institutions to this reality. I dont believe that transparency 
and democracy are antidotes to risk but they can constitute a fundamental element in reducing vulnerability to risks - both natural ones as well as technological ones.

\section{Luis David Castiel}

Qualquer proposta de transparência e democratização das sociedades, de modo que decisões políticas possam ser tomadas com conhecimento de causa, precisa considerar as informações e o grau de entendimento dos grupos sociais quanto às questões em foco. Isto é, envolve novas questões éticas relativas às técnicas biomédicas atuais e suas formas de transmissão à sociedade leiga. O biólogo francês Henri Atlan aponta três atores neste processo: cientistas, jornalistas e público. Nesta interface, os acadêmicos devem bustar o maior rigor possível em suas tentativas de comunicação, sem concessões à retórica do espetáculo. Ou seja, é necessário ressaltar a dimensão inescapavelmente provisória e restrita da pesquisa científica, evitando apresentações triunfalistas e explicações simplificadoras, através de imagens e metáforas redutivistas. Mas serão os cientistas capazes de se autocriticar e admitir as limitações de seu empreendimento? (H. Atlan e C. Bousquet, Questions de vie. Entre le savoir et l'opinion, Paris, Seuil, 1994).

Isto, per se, apresenta dificuldades, pois, na transformação de um achado científico em notícia, o chamado jornalismo científico tende a fazer uso justamente de formas retóricas que apelam para os aspectos já mencionados. E mesmo os cientistas podem utilizar tais recursos no afã de tornar acessiveis suas explicações. Temos, então, alguns problemas. Cabe aos cientistas participar dos processos de comunicação leiga de seus achados? A resposta será provavelmente afirmativa, pois há situações onde não é possível furtar-se às demandas dos meios de comunicação de massa. Mas aí se coloca a questão do 'como'?

Tem-se a impressão de que a grande maioria dos acadêmicos tende a ser vista pelos meios de comunicação de massa como emissores de discursos herméticos, repletos de jargão. Destinados, provavelmente, a gerar tédio ou desatenção nos espectadores, leitores, ouvintes etc. Especialmente, se levarmos em conta que cientistas não foram treinados para serem comunicadores sociais.

Temos, então, um dilema. Devem os acadêmicos se retirar da arena da comunicação leiga? Caso sim, como lidar com a responsabilidade da divulgação truncada/equivocada de seus trabalhos por outrem? Caso não, como participar de processos de difusão para os quais, em geral, não estão preparados? E, vale assinalar, o fato de não terem, em geral, acesso ao acabamento dos produtos finais (por exemplo, o problema dos formatos simplificadores nas 'edições' de suas intervenções).

Um sério problema no entendimento público de questões científicas que afetem o cotidiano reside nos conhecimentos de genética para orientar as decisões (tanto ao nivel individual como coletivo) quanto a testagens preditivas em relação a riscos de deficiências, doenças, malformações etc. localizados no genoma.

Há estudos realizados em países capitalistas avançados que evidenciam o amplo reconhecimento popular de expressões como DNA, cromossoma, gen, entre outras. Contudo, poucas pessoas manuseiam satisfatoriamente as noções mendelianas básicas para o entendimento de questões trazidas pela genética. Além disso, não costumam dispor de conhecimentos para relacionar idéias sobre hereditariedade a aspectos de suscetibilidade a determinadas doenças. Desse modo, expertos postulam a necessidade 
de se implementar propostas educacionais que ensejem a "alfabetização genética" das pessoas, como forma de propiciar elementos para que se posicionem de modo consistente diante dos debates sobre os novos desenvolvimentos tecnológicos. Isto deveria valer, também, para noções de probabilidade subjacentes à construção do conceito de risco: uma "alfabetização probabilística"?

Para haver transparência e democratização das decisões envolvendo ciência, tecnologia e riscos é preciso que as pessoas conheçam aspectos relativos a estas dimensões. Para tanto, deveriam participar de processos de aprendizagem que levassem em consideração as construções leigas existentes. Isto traz à cena uma série de questões que demandam encaminhamentos pertinentes. Por exemplo: quais processos educacionais, tanto em termos didáticos como pedagógicos, seriam capazes de "alfabetizar" as pessoas nas dimensões de ciência, tecnologia, riscos etc. relacionadas a suas (nossas) vidas? Especialmente se levarmos em conta quão precários são os mecanismos educacionais existentes, em termos da população geral. Qual seria o papel dos meios de comunicação de massa? Como participar destes canais? Somente através dos sistemas públicos de difusão? Como participar dos sistemas privados na educação em saúde? Como lidar com os distintos interesses envolvidos entre os vários atores - ao nível da oferta de serviços, da produção de tecnologia, das corporações profissionais, das políticas de saúde?

Enfim, encerro esta participação com mais indagações que certezas. Mas creio serem questões cruciais merecedoras de nossa reflexão para a definição do futuro imediato que poderemos construir, a despeito das perplexidades e dos turbilhões dos dias atuais.

\section{Marcelo Firpo de Souza Porto}

Esta última questão nos coloca diante do que denomino a dimensão metafísica do risco. A construção da ciência moderna e do industrialismo fundamentam-se numa ruptura com visões cosmológicas anteriores. A racionalidade moderna tende a transformar a natureza dos seres e do próprio universo em variáveis quantitativas, articuladas entre si por visões teóricas e modelos desenvolvidos por especialistas. Não existiriam Verdades, somente verdades transitórias e específicas aos diversos fragmentos de realidade apropriadas pelos vários ramos da ciência. Ao esquartejamento da razão tradicional co-movida segue-se a construção e difusão da razão moderna, base cognitiva do sistema científico e tecnológico do industrialismo. A ruptura entre conhecimento e sabedoria realizada pela racionalidade moderna e pela linguagem acadêmica dificulta a comunicação entre fato e valor, entre ciência e consciência. $\mathrm{O}$ sentido de palavras como amor, harmonia e realização, tão caras à maioria dos seres humanos, tende a ser desprezado pelo discurso científico.

Sob esta ótica, a crise ética contemporânea pode ser compreendida à luz de uma crise maior da própria razão humana. Um dos reflexos desta crise é o relativismo individualista tipicamente pós-moderno. Nele já não existem realidades 'reais'; só representações da realidade - simulacros criados pelo imaginário humano, individual ou coletivo. $\mathrm{Na}$ perspectiva desse relativismo, todos possuem o direito de criar suas próprias realidades como extensão máxima da liberdade individual.

A noção de risco pode ser apreendida de outra forma. Por exemplo, como expressão de um desequilíbrio mais profundo entre homem e natureza e na relação do homem 
consigo mesmo. Por isso, transparência e democracia ajudam - eventualmente muito! - no encaminhamento dos problemas. Mas sozinhas não respondem à perplexidade moderna frente aos riscos tecnológicos cada vez mais graves e globais. Não se trata de construir uma sociedade sem riscos - a rigor, risco zero é expressão última da própria morte - , mas de redirecionar a aventura humana para caminhos mais harmônicos que os atuais. Nesse sentido, o reconhecimento dos limites da ciência moderna e da gravidade dos riscos tecnológicos desempenham papel importante na abertura de novas portas e diálogos.

Para encerrar, gostaria de compartilhar uma história que se encaixa bem no tema deste debate. Um antigo conto da tradição oral sufi conta a história de um sábio e humilde barqueiro. Um dia, ao transportar um homem por águas revoltas, disse qualquer coisa que contrariava as regras gramaticais. "Você nunca estudou gramática?", perguntou o pedante erudito. Ao escutar a negativa do barqueiro, pontificou: "Nesse caso, a metade de sua vida se perdeu." Minutos depois, o barqueiro voltou-se para o passageiro e perguntou: "Você sabe nadar ?" "Não. Por quê?" E o barqueiro explicou: "Porque, nesse caso, toda a sua vida se perdeu. Estamos afundando." 